\title{
BILATERAL THORACIC PARAVERTEBRAL BLOCK COMBINED WITH SEDATION AS THE SOLE ANESTHESIA TECHNIQUE FOR SURGICAL DRAINAGE OF PERICARDIAL EFFUSION IN CRITICALLY ILL PATIENT (ASA IVE)
}

\section{A.Y. Ghidan ${ }^{1}$, Y. Shibata ${ }^{1}$, N. Shota ${ }^{2}$.}

${ }^{1}$ Nagoya University Hospital, Department of Anesthesiology- Graduate School of Medicine., Nagoya, Japan.

${ }^{2}$ Nagoya University Hospital, Department of Thoracic Surgery-Graduate School of Medicine., Nagoya, Japan.

\section{Introduction}

Thoracic Paravertebral Block is the technique of injecting local anesthetic adjacent to the thoracic vertebra close to where the spinal nerves emerge from the intervertebral foramina ${ }^{[1]}$. This technique produces ipsilateral, segmental, somatic, and sympathetic nerve blockade in contiguous thoracic dermatomes ${ }^{[1]}$.

It can be used unilaterally or bilaterally, with a single level injection technique or multiple level injections technique

Background and Aims: We report here the use of bilateral multiple level injections ultrasound-guided TPVB combined with sedation as a sole anesthesia technique for critical ill patient (ASA IVE) undergoing pericardial drainage by lower midline chest incision. Hemodynamic instability is the major concern in surgical patients with pericardial diseases. In addition to malignant mesothelioma our patient have CHF (NYHA3),AFib and right side pnemothorax. Anesthesia in such patients requires special attention because of low cardiac capacity and respiratory function. Effectively blocking pain pathways is important to control the heart rate and prevent postoperative respiratory compromise. The aim was to avoid general anesthesia by providing bilateral TPVB without any complications.

Methods:We planned to perform bilateral multiple level injections ultrasound-guided TPVB at level of T6 and T7. Using transversal technique at the articular process view Inplane for one side and the sagittal technique at the transverse process view In-plane for the other side. The proper placement of the needle in the paravertebral space was confirmed with hydrolocation then $0.25 \%$ Ropivacaine $10 \mathrm{ml}$ injected after negative aspiration of blood or air. Total amount: $40 \mathrm{ml}$ of $0.25 \%$ Ropivacaine (10 ml each injection)

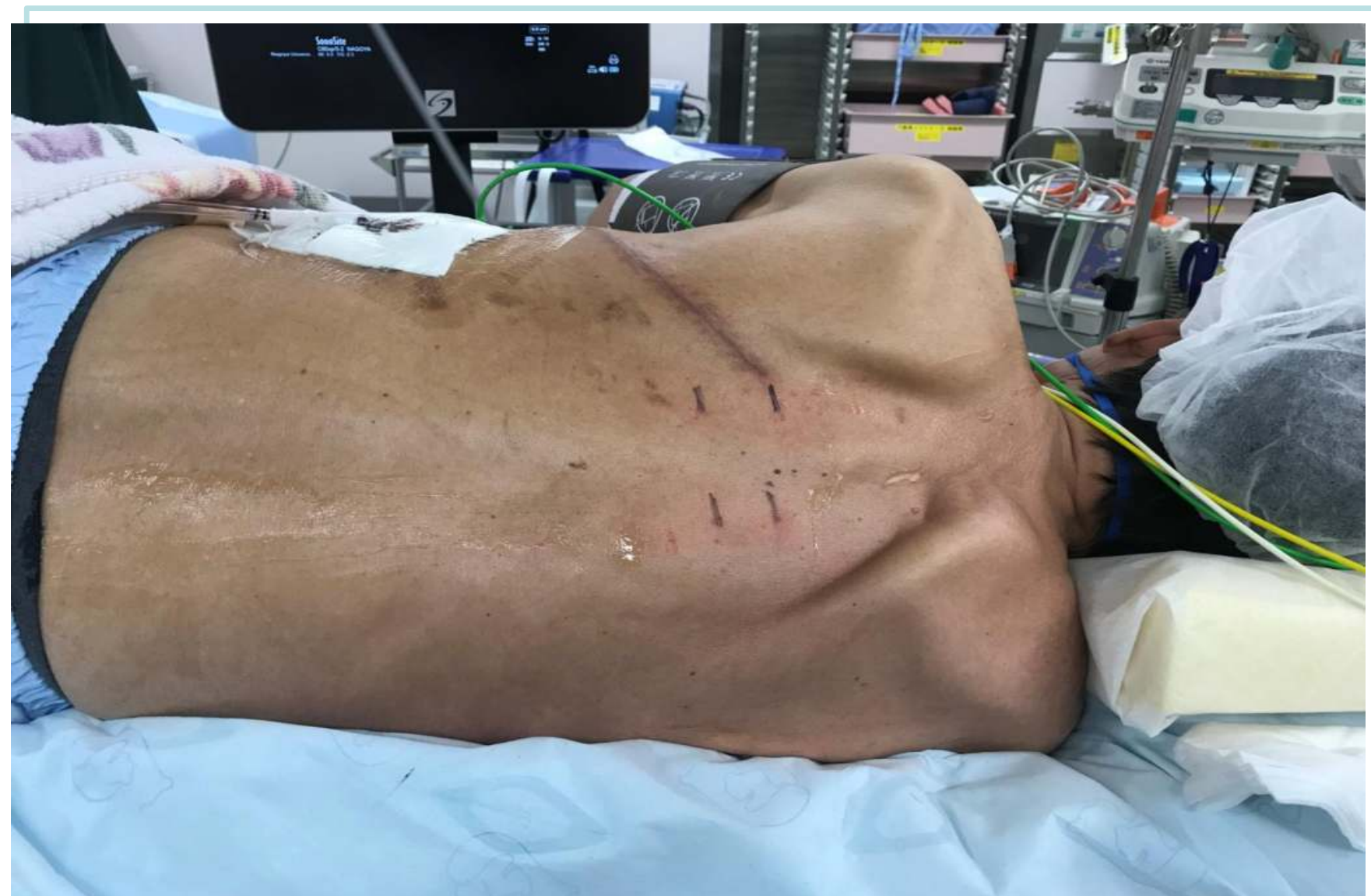

Results: No complications occurred. At the end of surgery the patient was comfortable, free of pain until postoperative day 2 (pain score 2-3/10) and discharged home after 24 days without any complications.

Conclusions: For patient with limited cardiac reserve due to pericardial effusion, bilateral TPVB as the sole anesthesia technique should be strongly considered for performing surgical pericardial drainage when general anesthesia is not desirable and this is a novel indication for bilateral TPVB and new Anesthestic management for pericardial drainage.

\section{Consent}

The patient consent was obtained

\section{Conflict of Interests}

No conflict of interes

\section{Keywords}

BILATERAL THORACIC PARAVERTEBRAL BLOCK. NEW ANESTHETIC MANAGEMENT FOR PERICARDIAL DRAINAGE.

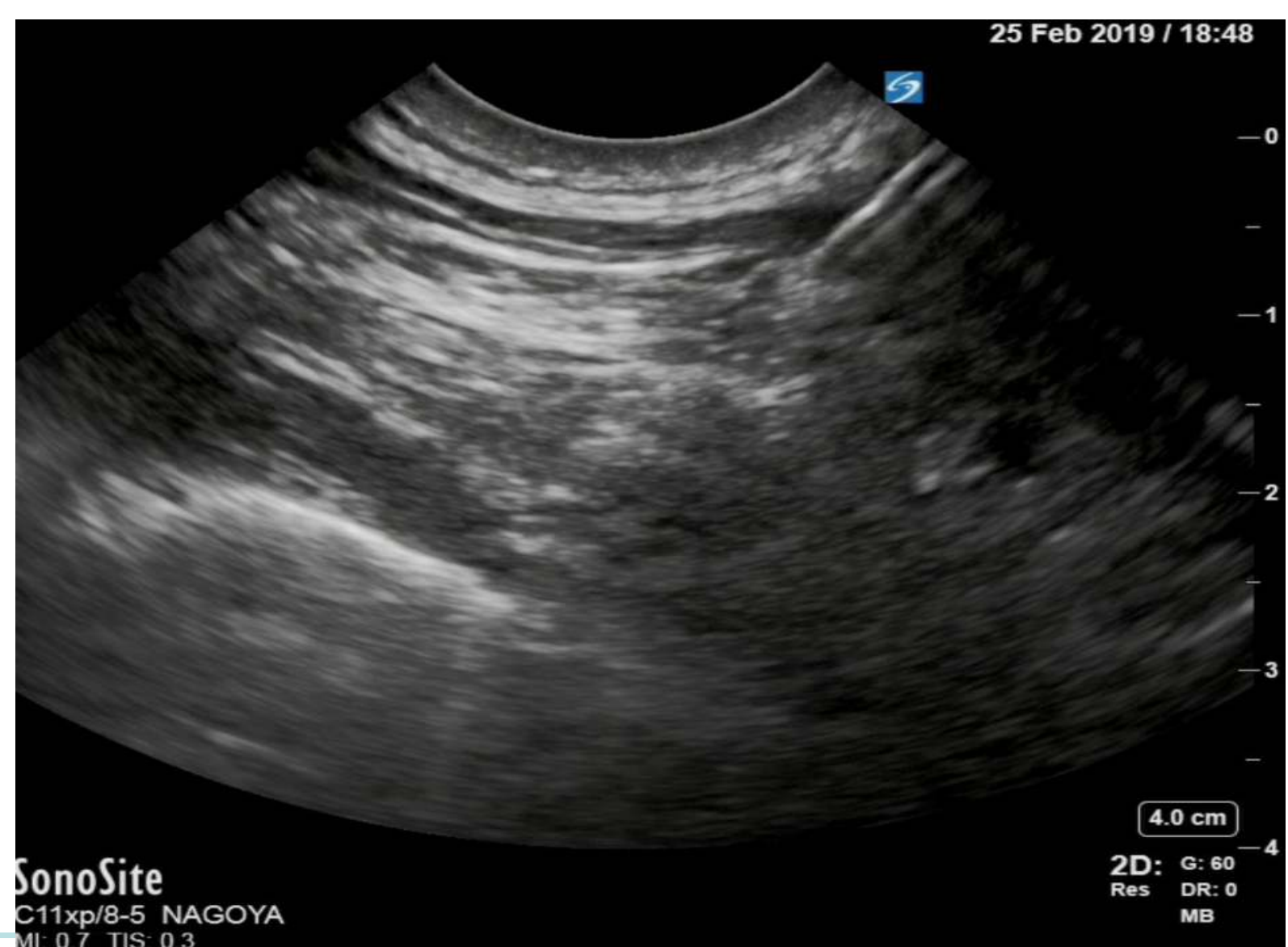

